Table 1

Mean and Percent Correct of Clear and Degraded Items on Recall and Recognition for Each Group

\begin{tabular}{lccccc} 
& \multicolumn{2}{c}{ Recall } & \multicolumn{2}{c}{ Recognition } \\
\cline { 2 - 5 } & (Clear & Degraded & & Clear & Degraded \\
\hline Group V & $.08(.01 \%)$ & $.00(0 \%)$ & $2.50(36 \%)$ & $1.75(25 \%)$ \\
Group VR & $.75(11 \%)$ & $.42(6 \%)$ & $5.08(73 \%)$ & $5.08(73 \%)$ \\
\hline
\end{tabular}

Table 1 shows the means and percentages of correct recall and recognition for the clear and degraded items in each subgroup. A Mann-Whitney $U$ test on the combined recall (with the three letters in their proper order) of items that were clear and of items that were degraded on original presentation showed that Group VR correctly recalled more jtems than did Group V ( $p<.02)$, but there was no significant difference, as measured by a sign test, in recall of Group VR due to item degradation. The two recognition scores for each $S$ were the total number of correct identifications of items that were clear and of items that were degraded on original presentation. An analysis of variance of the recognition scores yielded a highly significant difference due to instructions $[F(1,22)=44.50, \quad p<.001]$, with Group VR being superior to Group V. The main effect of visual degradation and the interaction of this variable with instructions lacked significance.

Because of the poor recognition performance of $S s$ in Group V, individual $t$ tests were performed on the clear and degraded conditions within this group to determine if recognition performance in either condition was above the chance value of 1.75 items correct. The mean performance on the clear items $(\bar{X}=2.50)$ was found to be significantly greater than chance $[t(11)=2.88, p<.02]$, while the mean performance on the degraded items $(\bar{X}=1.75)$ was equal to chance.

\section{DISCUSSION}

The hypothesis that a visually degraded stimulus will leave a poorer reference trace, and in turn yield poorer recognition performance was not supported by analysis of variance. However, it was found that performance on the clear items for Group V was superior to chance, while perfornance on the degraded items was not, so some support for the hypothesis was obtained.

Support was found for the hypothesis that increasing the number of modalities used during both acquisition and testing improves recognition performance. The occurrence of responses during acquisition appears to lay down supplementary perceptual traces whose activation at the time of testing benefits recognition.
Pilot testing gave the expectation that recall scores for Groups $\mathrm{V}$ and VR would be essentially zero, and the level of recall was very low. Group VR had significantly more items recalled than Group $V$, but the fact remains that mean correct recall for Group VR was only $1.17(8 \%)$ items. It seems unlikely that the recall capability
A number of investigators working with undergraduate college students (e.g., Weiss \& Margolius, 1954; Saltz, 1963) and children (Baumeister \& Berry, 1968) have reported that addition of an item-specific color cue to the stimulus or stimulus and response members of a pair facilitates verbal paired-associate learning. In a study that used two types of contextual cues (shape and color) instead of one, and college students as Ss, Swede \& McNulty

* The authors are indebted to Natalie Coleman and William Frank for their assistance in data collection and to Dr. Robert Earl for many helpful discussions. The opinions or conclusions stated in this paper are those of the authors and are not to be construed as official or as necessarily reflecting the policy of the Department of Mental Hygiene. biased the comparisons or detracted appreciably from the concern with stimulus recognition.

\section{REFERENCES}

ADAMS, J. A. Human memory. New York: McGraw-Hill, 1967.

ADAMS, J. A. Response feedback and learning. Psychological Bulletin, 1968, 70, 486-504.

ADAMS, J. A., \& BRAY, N. W. A closed-loop theory of paired-associate verbal learning. Psychological Review, in press.

ESTES, W. K., \& DaPOLITO, F. Independent variation of information storage and retrieval processes in paired-associate learning. Joumal of Experimental Psychology, 1967, 75, 18-26.

WTMER, $L$. R. The association value of three-place consonant syllables Joumal of Genetic Psychology, 1935, 47, 337-360.

\title{
Stimulus compounding vs social reinforcement in adult paired-associate learning
}

\author{
JOHN HANNON, MARY JANKE, and MEREDITH DAVISON \\ California Department of Mental Hygiene \\ Stockton State Hospital, Stockton, Calif. 94202
}

Twenty-eight adult Ss were tested in a paired-associate learning task using the method of anticipation, each S learning four lists of eight nonsense-syllable/adjective pairs under four counterbalanced conditions. One list was accompanied by item-specific color and flicker, another by nonitem-specific color and flicker. Still another list was accompanied by neither color nor flicker, but $S$ was socially reinforced after each correct response. The fourth list did not involve color, flicker, or reinforcement. Item-specific color and flicker facilitated learning; the other three conditions did not differ reliably.

(1967) found an even greater facilitative effect of the two dimensions of cues combined than of shape or color alone. However, in work with one type of contextual cue, Sundland \& Wickens (1962), who studied college students, and Baumeister \& Berry (1968), who studied mentally retarded children and youths, did not observe such an effect. The purpose of this experiment was to see if a facilitative effect of two types of contextual cues is observed in mature adults in a noncollege environment, and to compare their relative learning (or performance) efficiencies under this condition and under social reinforcement.

Results on the effectiveness of reinforcement in the paired-associate learning of normal Ss are mixed. Spence, Goodstein, \& Lair (1965) reported that 
social reinforcement interfered with the performance of fast learners but facilitated that of slow learners. Their S group was heterogeneous; the response measure used was number correct. Harley (1965) and Keller, Cole, Burke, \& Estes (1965) found no effect of monetary reinforcement on the learning of college student Ss. On the other hand, Kanfer \& Matarazzo (1959) reported that student nurses reached criterion on a paired-associate task significantly more slowly when reinforced with nonredeemable poker chips than they did when chips could be redeemed for gifts.

Two kinds of control conditions were investigated, one being a standard paired-associate learning paradigm (anticipation method). The other control condition incorporated two types of contextual stimuli that remained constant for each pair and thus were not item-specific; this was to determine if the presence of contextual cues might owe some of its effect to generalized arousal (Berlyne, 1967) rather than to item specificity of the cues themselves.

\section{SUBJECTS}

The Ss were 28 employees of Stockton State Hospital, ranging in age from 20 to 55 , who participated voluntarily in the experiment. They included 3 men and 25 women.

\section{MATERIALS, APPARATUS, AND PROCEDURE}

Four lists were constructed, each consisting of eight pairs. Stimuli were CVCs of low $m$ selected from Archer's (1960) table. Responses were adjectives designated as 1 (one or more than one occurrence per million words of printed text and less than two occurrences) in the Thorndike-Lorge (1944) word count. Each pair was printed in capital letters, $1 / 4 \mathrm{in}$. high, on a $5 \times 8$ in. plain file card, to make 12 decks of cards (four lists, three conditions for each list). For the item-specific compound-stimulus condition, each pair, printed in black ink, was surrounded by construction paper of a different color (red, purple, yellow, brown, green, blue, black, pink). Pairs were projected onto a screen about $10 \mathrm{ft}$ in front of the $S$ by means of an opaque projector, and during the exposure of each pair the projector lamp was flickered in a prearranged item-specific pattern by means of a manually operated switch. In the nonitem-specific, or cueless, compound-stimulus condition, all pairs were printed in purple ink and surrounded by pink construction paper; the projector lamp flickered in the same pattern for each pair. For the social reinforcement condition, pairs were printed in black and not accompanied by color or flicker. Instead, one E said, "Good," "Right," etc., immediately following each correct response by $\mathrm{S}$. (Two Es were required to operate the apparatus.) The neutral condition was identical with the reinforcement condition with regard to stimulus materials and presentation, but $E$ made no comments to $S$ regardless of the correctness of S's response.

Standard anticipation instructions were given; no mention was made in the instructions of color or flicker. Each $S$ was run individually, and each learned four lists, one under each condition, on 4 successive days. Order of lists and assignment of conditions to lists was counterbalanced in a Greco-Latin square design replicated seven times. Learning proceeded to a criterion of 1 errorless trial or 12 trials on a list, whichever occurred first.

Exposure time was $5 \mathrm{sec}$ for the stimulus item alone and $5 \mathrm{sec}$ for stimulus and response together. Interpair intervals were approximately $3 \mathrm{sec}$, and intertrial intervals (during which the cards in the deck were shuffled) were approximately $10 \mathrm{sec}$.

\section{RESULTS}

Analysis of variance was performed on error scores. The effect of order was not significant, as hoped. The effect of treatment condition was significant ( $F=4.87, \mathrm{df}=3 / 78, \mathrm{p}<.01$ ), as was the effect of days $(F=14.58$, df $=3 / 78$, $\mathrm{p}<.01$ ), indicating a substantial practice effect. Treatment means were 19.9 for the item-specific compound stimulus condition (I), 25.2 for the neutral condition $(\mathrm{N})$, 26.6 for the cueless compound stimulus condition (C), and 28.2 for the reinforcement condition (R). Analysis of these differences by means of $t$ tests for correlated samples indicated that I was significantly superior to $\mathrm{N}(\mathrm{t}=1.9, \mathrm{df}=27$, $\mathrm{p}<.05), C \quad(\mathrm{t}=2.2, \mathrm{df}=27, \mathrm{p}<.025)$, and $R \quad(t=2.9, \quad d f=27, \quad p<.01, \quad a$ two-tailed test). The three inferior conditons were not significantly different from one another.

Separate analyses of trials to criterion were not made, as results were in the same direction but differences were not nearly so great. This is, in part, attributable to the procedure of cutting off slow learners after the 12 th trial.

Error scores for the four treatment conditions were ranked for each of the eight Ss making the fewest errors, subject to the restriction that each of the four treatment orders be represented by two Ss, and for each of the eight Ss making the most errors, subject to the same restriction. A similar procedure was followed for trials to criterion, calling the number of trials $13+$ if $S$ had not reached criterion within 12 trials. Analysis of variance by ranks showed no significant differences among treatment rankings for either group or response measure.

\section{DISCUSSION}

Results show that under the conditions of this experiment item-specific contextual cues in two stimulus dimensions facilitate the verbal paired-associate learning of mature Ss. Social reinforcement, on the other hand, does not facilitate such learning.

The lack of a significant difference in rankings of the various treatments for fast as opposed to slow learners is probably due in part to the strong practice effect. Nevertheless, the trend of these rankings, with respect to errors, was not consistent with Spence, Goodstein, \& Lair's (1965) findings of a differential effect of social reinforcement on these two groups of $\mathrm{Ss}$, although greater consistency was obtained when trials to criterion was used as a response measure. We intend to explore the matter in further studies in which the practice effect will be minimized.

\section{REFERENCES}

ARCHER, E. J. A re-evaluation of the meaningfulness of all possible CVC trigrams. Psychological Monographs, 1960, 74(10, Whole No. 497).

BALMEISTER, A. A., \& BERRY, F. M. Context stimuli in verbal paired-associate learning by normal children and retardates. Psychological Record, 1968, 18, 185-190.

BERLYNE, D. E. Arousal and reinforcement. In D. Levine (Ed.), Nebraska symposium on motivation. Lincoln: University of Nebraska Press, 1967. Pp. 1-110.

HARLEY, W. F., JR. The effect of monetary incentive in paired associate learning using an absolute method. Psychonomic Science. 1965. $3,141-142$

KANFER, F. H., \& MATARAZZO, J, D. Secondary and generalized reinforcement in human learning. Journal of Experimental Psychology, 1959, 58, 400-404.

KELIER, L., COLE, M., BURKE, C. J., \& ESTES, W. K. Reward and information values of trial outcomes in paired-associate learning. Psychological Monographs, 1965, 79(12, Whole No. 605).

SALTZ, E. Compound stimuli in verbal learning: Cognitive and sensory differentiation vs stimulus selection. Journal of Experimental Psychology, 1963, 66, 1-5.

SPENCE, J. T.. GOODSTEIN, L. D.. \& LAIR, C. $V$. Rote learning in schizophrenic and normal subjects under positive and negative reinforcement conditions. Journal of Abnormal Psychology, 1965, 70, 251-261.

SUNDLAND, D. M., \& WICKENS, D. D. Context factors in paired-associate learning and recall. Joumal of Experimental Psychology, 1962, $63,302-306$.

SWEDE, G., \& McNLLTY, J. A. The influence of contextual cues upon the learning and retention of paired associates. Canadian Journal of Psychology, 1967, 21, 394-408.

THORNDIKE, E. L., \& LORGE, I. The teacher's word book of 30,000 words. New York: Bureau of Publications, Teacher's College, Columbia University, 1944.

IV -.SS, W., \& MARGOLIL'S. G. The eftect of context stimuli on learning and retention. Journal of Experimental Psychology. 1954. $48,318-322$. 